\section{Rock rural:}

origens,

estrada e destinos
LUIZ CARLOS SÁ

é músico, integrante

da dupla

Sá \& Guarabyra,

e jornalista.

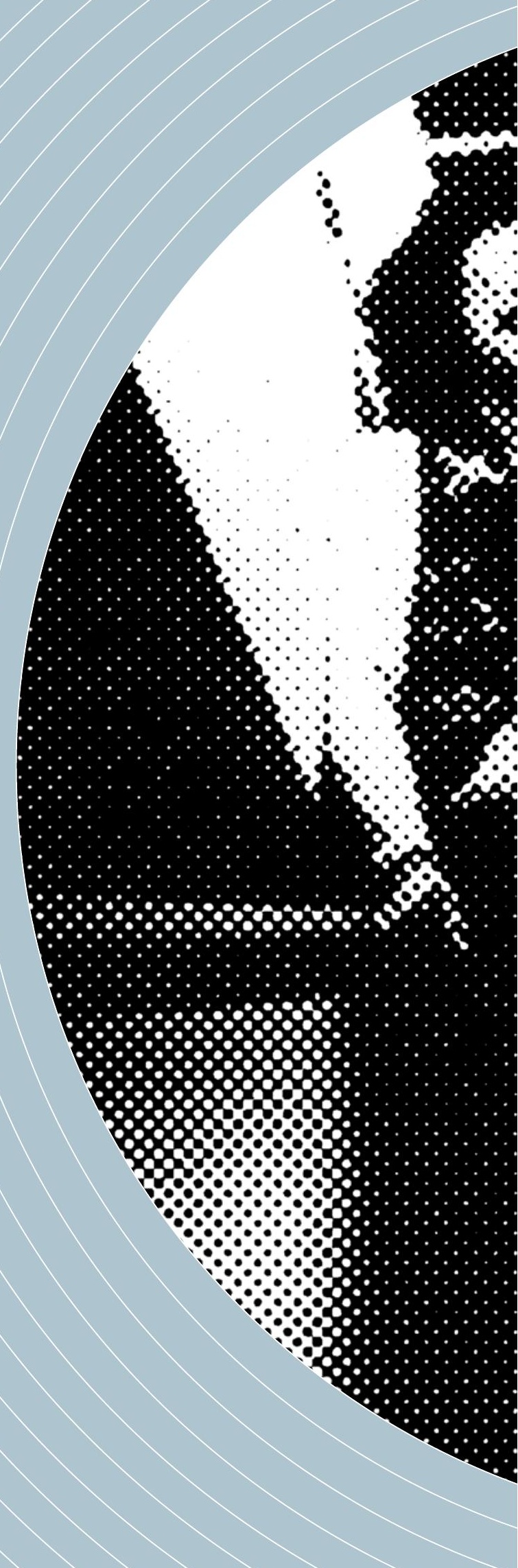



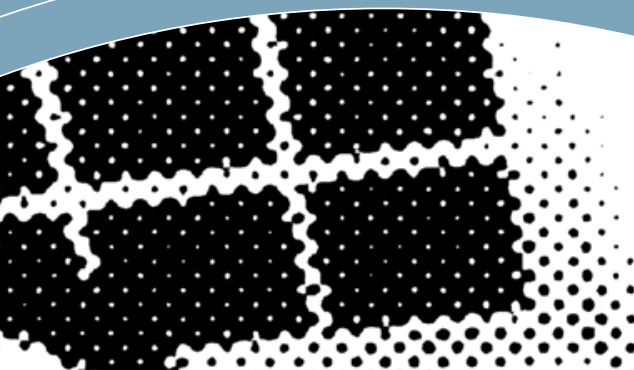

\% 3 क \& \$ \$ \& \& $\quad \& \&$ \% $\quad$ \% \% 1 , .

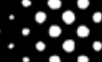
8 8

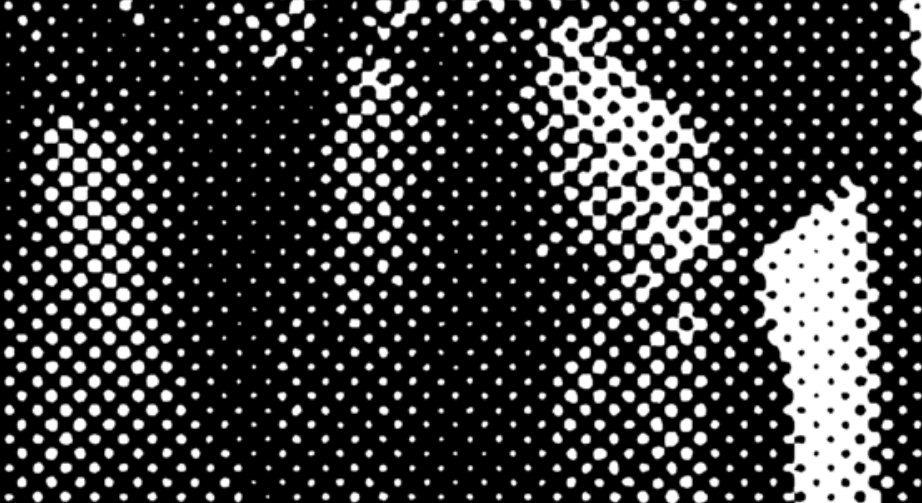




\section{RESUMO}

O rótulo"rock rural"é somente um rótulo ou pode ser considerado uma definição veraz para o estilo musical do trio Sá, Rodrix \& Guarabyra, da consequente dupla Sá \& Guarabyra e de seus eventuais seguidores? É um nicho importante dentro do desenvolvimento da música popular ou limitou-se à esfera de ação de seus criadores? De onde veio e para onde vai o rock rural, se nem sempre ele é rock e nem sempre é rural? Ele é um sucesso comercial ou não? Quem ouviu, ouve e ouvirá o rock rural? Ele ainda toca em rádio? Por que o rock rural não pôde ocupar o espaço das duplas "sertanejas"? A mídia leva o rock rural a sério como levou a sério o tropicalismo? O rock rural é um tipo de antropofagia cultural semelhante ao citado tropicalismo ou limita-se a emular uma cultura alienígena? Por que - e como - o rock rural perdura e sustenta seus criadores há quase quarenta anos sem jamais ter frequentado a mass media?

Palavras-chave: rock rural, mercado de discos, mass media.

\section{ABSTRACT}

Is "rural rock" merely a label or can it be considered an accurate definition of the musical style of the trio Sá, Rodrix \& Guarabyra, of the duo Sá \& Guarabyra - formed after Rodrix split - and of their later followers? Is it an important niche in the process of popular music development or is it limited to what its creators have done? As it is not always rock and not always rural, where did rural rock come from and where is it going to? Is it commercially successful? Who listened to rural rock, who does it now and who will listen to it? Is it still played on radio? Why didn't rural rock manage to take up the space granted to "country" duos? Do media take rural rock seriously as it did with tropicalism? Is rural rock a sort of cultural anthropophagy similar to that of tropicalism or is if just an emulation of an alien culture? Why-and how-has rural rock lasted and supported its creators for almost forty years without ever been in the mass-media on a regular basis?

Keywords: rural rock, record market, mass media. 
ock rural" é antes de tudo um rótulo criado pela mídia a partir da letra de "Casa no Campo" (Tavito e Zé Rodrix, 1971) - “Eu quero uma casa no campo onde eu possa compor muitos rocks rurais...". Gravada por Elis Regina com estrondoso sucesso, a música de Rodrix e Tavito invadiu o imaginário sonhador de toda uma geração incomodada pelo súbito ingresso do país numa escala industrial e capitalista iniciada pela era JK e embalada pela necessidade da ditadura militar de afirmar-se como "progressista". Ao mesmo tempo, duramente impedida de manifestar-se em liberdade, a juventude brasileira egressa dos tempos de passeatas e luta armada era forçada a derivar então para um tipo de contestação inspirada pelo movimento hippie, que nos EUA tinha uma força contestatória muito mais evidente, contrária à Guerra do Vietnã. Mas enquanto os sistemas repressivos europeus e americanos tinham que se ater a leis constitucionais e à democracia vigente, no que pesem os assassinatos de Chicago e Paris, nós aqui sofríamos a ausência do estado de direito. Por isso, enquanto o "flower power" vicejava nos Estados Unidos e na Europa como uma força ideológica de fato, impondo suas exigências por vias políticas e através de importantes movimentos de massa que acabaram, por exemplo, demolindo o apoio popular ao intervencionismo americano na Ásia e ao tradicionalismo do ensino acadêmico francês, nós brasileiros tínhamos que nos conformar com o que a 
ditadura julgasse menos danoso a seus objetivos. Daí nasceram as alusões musicais à escravidão, na pós-bossa nova de Edu Lobo, Ruy Guerra, Vinícius, Baden Powell, Nara Leão e muitos outros, que se utilizavam da metáfora da escravidão para intuir uma série de noções de igualdade social que foram relativamente toleradas pela ditadura até o AI-5 de 1968, que enterrou definitivamente a então chamada "música de protesto". $\mathrm{Na}$ mesma época, o nascente tropicalismo de Caetano, Gil, Gal, Torquato e similares foi extrapoladamente reprimido com prisões e torturas, mais pela postura estética e libertária de seus líderes do que propriamente pela ameaça às então reinantes instituições. De 68 a 71 o que se ouviu na música brasileira foi o silêncio, quebrado aqui e ali por meia dúzia de contestadores mais persistentes que se expunham à repressão ou pelos interesses meramente comerciais que governavam as rádios.

Enquanto isso, eu e Rodrix partíamos da "Casa no Campo", influenciados pelos novos ventos musicais que nos eram trazidos por James Taylor, Leon Russell, Carole King, Eagles, Beatles e muitos outros oriundos do folk e country rock e fazíamos o

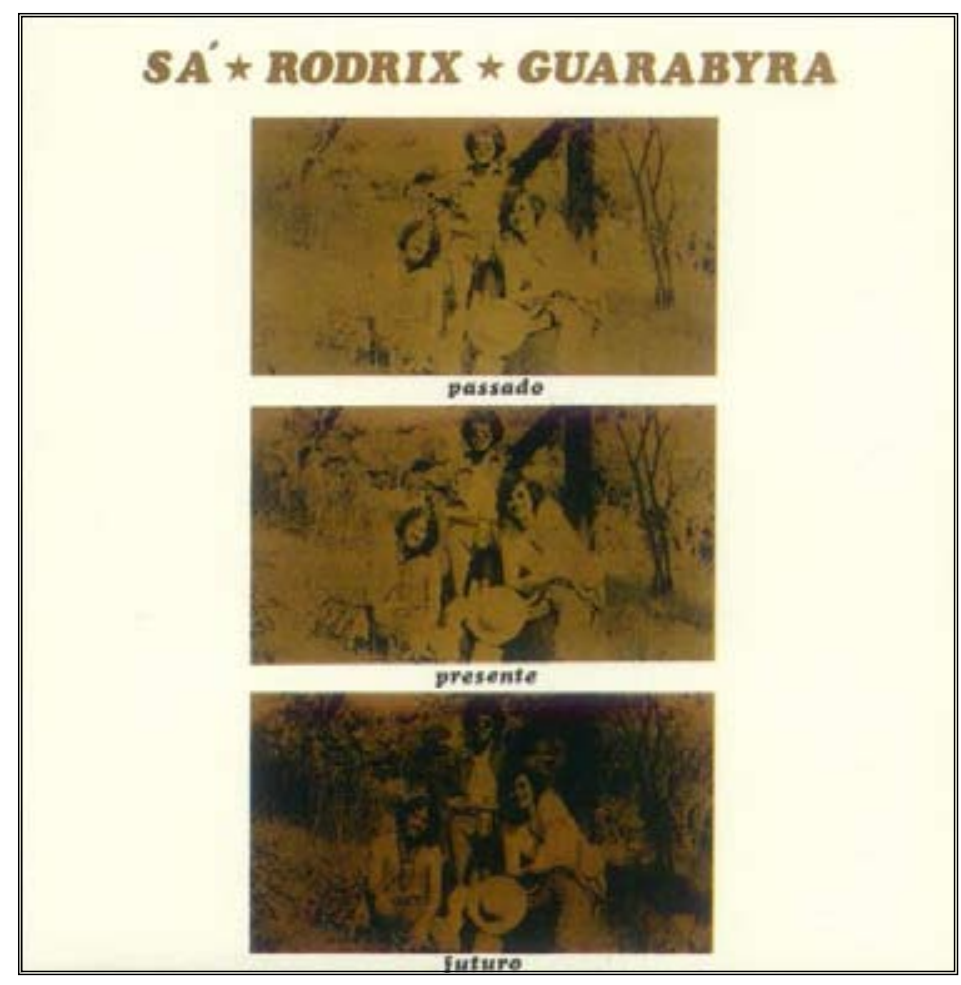

que era mais ou menos permitido para fugir daquilo que estava ali. Nesse entretempo, recém-separado de um casamento, fui literalmente resgatado por Guarabyra na Praça da Paz, em Ipanema, onde eu estacionara meu buggy Gurgel com as sobras do ex-lar. Guarabyra convidou-me para ir morar num apartamento ali perto - na Rua Alberto de Campos-, que ele dividia comos jornalistas José Trajano e Toninho Neves. O convite foi imediatamente aceito. Eu e Rodrix passamos então a ensaiar e compor na Alberto de Campos, já que, com o nascimento de Marya, sua primeira filha, ficara complicado ensaiar em sua casa. Velhos amigos e também parceiros de Guarabyra, pouco demorou para que transformássemos a dupla em trio. Guarabyra veio contribuir com suas raízes do sertão do médio São Francisco, carregadas de uma Bahia diferente de tudo que conhecêramos antes.

Nossa casa era frequentada por todo tipo de gente, de jornalistas e músicos a jovens atrizes e atores em começo de carreira, a maioria deles entusiasmada com nosso trabalho, o que acabou por nos conscientizar de que estávamos conseguindo trilhar um caminho diferente daqueles até então explorados no panorama musical da época. O produtor Mariozinho Rocha e o crítico musical do Jornal do Brasil Julio Hungria, habituês das nossas sessões musicais, nos estimularam a abandonar todo e qualquer outro projeto que porventura tivéssemos em prol de uma dedicação exclusiva ao trio. Mariozinho nos garantiu o apoio da Odeongravadora daqual jáéramos individualmente contratados - e Júlio escreveu seu primeiro artigo sobre o nascente trio, em que descreveu nosso som como "caipira progressivo". O nome artístico - feito de sobrenomes - veio por inspiração da nossa principal influência exterior, o trio Crosby, Stills \& Nash: nascia assim Sá, Rodrix \& Guarabyra.

Quando começamos a compor tendo o disco por objetivo, nossas parcerias se consolidaram com mais firmeza. Decidido o nome do LP-Passado, Presente, Futuro, porque queríamos fazer algo atemporal, longe de modismos -, chamamos nossos amigos Waltercio Caldas Jr. para a concep- 
ção gráfica e Amarílio Gastal para fazer as fotos. Waltercio já era então uma grande promessa das artes plásticas e concebeu uma capa com a repetição da mesma foto em três níveis de contraste que representavam os três tempos que queríamos "in-definir". Criou também as três árvores ligadas que serviram de logo para o trio até o último CD. Rodrix encarregou-se - brilhantemente, aliás, para um jovem arranjador ainda inexperiente - dos arranjos de orquestra e chamamos para tocar conosco nossos jovens amigos músicos da noite carioca: Pedrinho Poeta, Nelson Ângelo, Fernando Leporace, Sérgio Magrão, Luiz Moreno e outros de uma novíssima geração que começava outro capítulo da música popular brasileira, mesmo à sombra, ou talvez até por isso, da ditadura, já que parece que, quanto mais reprimido o ser humano, maior sua necessidade de expressão artística. A Odeon, contando com a inteligência e a sensibilidade de seu diretor artístico Milton Miranda, elemento-chave naquela fase brilhante da gravadora, deu-nos todo o apoio possível. O disco foi um sucesso imediato de público e crítica, saudado unanimemente como algo de inovador mesmo dentro do efervescente cenário musical do início dos anos 70. Além disso, tínhamos um grande trunfo a nosso favor: cada um de nós compunha música e letra, o que elevava em proporção geométrica nossas probabilidades de fazermos coisas boas, não só completando o trabalho inacabado do outro como também policiando sem pena os erros cometidos pelo(s) parceiro(s). Esse rigor, mais tarde, seria em grande parte a paradoxal causa de nossa separação.

$\mathrm{Na}$ realidade o que fizemos de mais acertado foi justamente mirar na demolição de certos preconceitos arraigados naquele público jovem-classe-média-universitária que nos acolheu de princípio: enquanto Rodrix ressuscitava o então desprezado acordeão e partia também para a execução de instrumentos vistos como "exóticos", como cravo, celesta, harpsicórdio, etc., eu eletrificava e experimentava diferentes afinações na viola caipira de dez cordas, antes esnobada como instrumento menor,

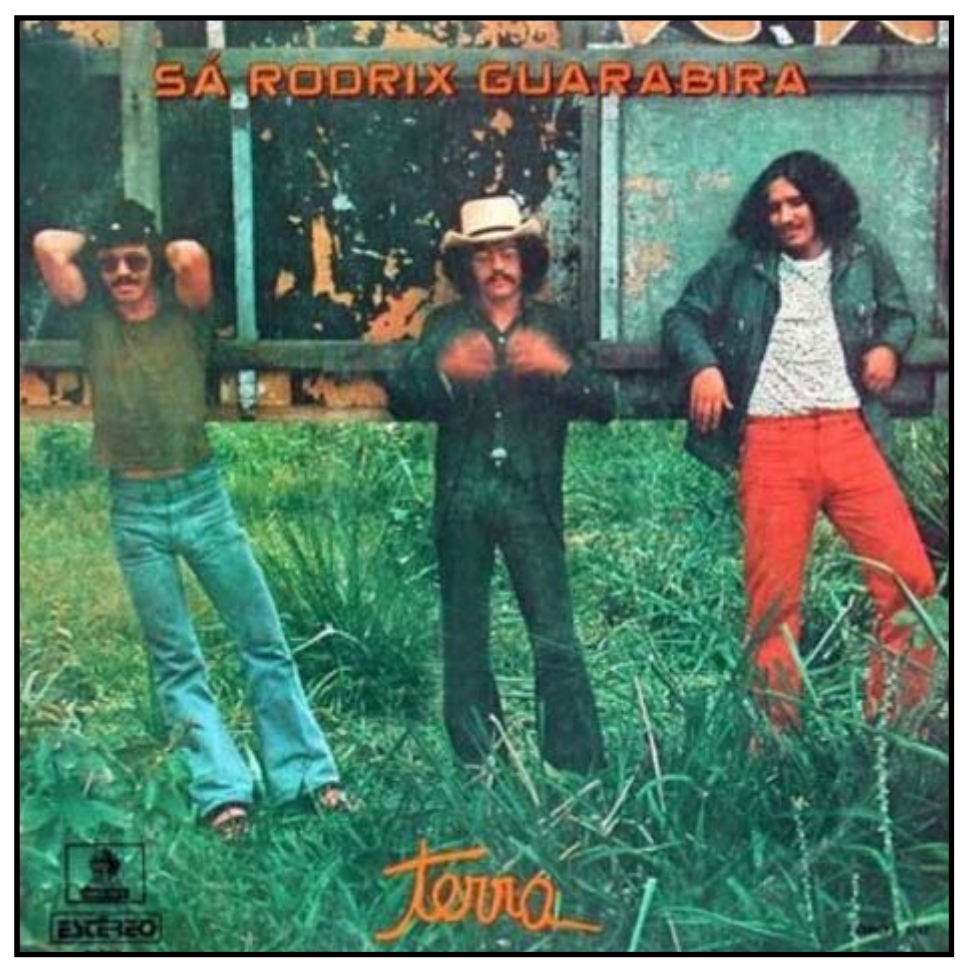

enquanto Guarabyra resgatava os sons das barrancas do São Francisco, largamente ignorados por um país que - ancorado no eixo Rio-São Paulo - não conhecia o Brasil real. Dessa mistura de três cabeças de formação e direções aparentemente divergentes foi que surgiu o que se pode chamar de rock rural.

As rádios do Brasil inteiro executavam "Hoje Ainda É Dia de Rock" (Rodrix) que, dizendo "Eu tô doidinho por uma viola, mãe e pai/ De doze cordas e quatro cristais/ Pra eu poder tocar lá na cidade, mãe e pai/ Esse meu blues de Minas Gerais”, caracterizava sucintamente nossa ambiguidade urbanorural, acústico-elétrica, roqueiro-caipira.

Mas como é de praxe acontecer em noventa por cento dos novos grupos surgidos nas últimas décadas, o segundo disco nos pegou de calças curtas. Parecia que cada um de nós queria partir para um objetivo diferente. Terra teve mais uma vez a concepção gráfica de Waltercio Caldas Jr., agora com a parceria fotográfica de Miguel Rio Branco, mas no meio das gravações Rodrix confessou-se insatisfeito com o que acreditava ser sua pequena participação no trabalho. À custa de muita conversa e
Sá, Rodrix

\& Guarabyra,

Terra,

EMI-Odeon,

1973 
apoiados mais na amizade do que na unidade musical conseguimos fazer de Terra um trabalho coerente e bem-acabado, e o rock rural continuava seu caminho, agora mais estradeiro ainda, reflexo das viagens que fazíamos para shows e da minha ida com Guarabyra ao médio São Francisco, viagem que marcou profundamente minha criação musical. Esse aspecto "estradeiro" do rock rural é reflexo direto desse prazer que sempre tivemos e ainda temos em viajar de carro. Naquele tempo, Rodrix era o mais ocupado de nós, já que se dedicava também a trabalhos externos ao trio. Mas eu e Guarabyra rodamos juntos meio Brasil, principalmente pela região do São Francisco, e essas viagens foram essenciais para que criássemos uma firme ligação solidária e, mais tarde, com a saída de Rodrix e o consequente desmanche do trio, acabássemos por continuar em dupla.

Logo após o lançamento de Terra fomos chamados a São Paulo por Rogério Duprat, que abriu a possibilidade de trabalharmos comele na área da publicidade. Eu, em particular, carioca convicto, não me entusiasmei muito com a perspectiva de mudar de cidade, mas acabei convencido pelos argumentos de meus parceiros: a mudança revitalizaria o trio e nos daria a oportunidade de trabalhar, conviver e aprender com Duprat, a quem admirávamos pessoal e musicalmente. Mas a mudança acabou sendo mais um fator de separação: enquanto eu, Guarabyra e a banda que tínhamos levado junto conosco para trabalhar e morar em São Paulo (Flávio Venturini, Luiz Moreno, Sérgio Magrão, Cezar de Mercês e Sérgio Hinds) optamos pelo Brooklyn, Rodrix preferiu morar mais para o Centro, na Brigadeiro Luiz Antonio. Insignificante hoje em dia, esse isolamento geográfico dentro da mesma cidade, acrescentado a uma mal planejada e malsucedida excursão ao sul do país, acabou por decretar nossa separação. Premido pela inadaptação de minha família ao inverno paulista, pela perda de credibilidade que sofrêramos devido à nossa entrada no mundo publicitário e pelos seguidos desentendimentos entre nós, voltei para o Rio, depois de amargas discussões com Rodrix, que ficou em São
Paulo e optou por retomar a carreira solo. Propus à Odeon a gravação de um single - que, ironicamente, teria minha primeira parceria com Rodrix, "Povo do Ar", como peça principal e comecei a pensar no que seria o rock rural a partir de mim. Minha ideia era seguir num caminho pop com qualidade suficiente para garantir-me a sobrevivência ideológica, que ficara sensivelmente prejudicada pela "contaminação" publicitária, rejeitada por nosso público contestador. Gravei então uma composição minimalista, "O Homem de Neanderthal", que para não ficar tão minimalista assim ganhou, em minha versão, uma segunda parte (foi depois regravada em sua versão original por Ney Matogrosso), com "Povo do Ar" completando o lado B. Tudo muito mais para rock que para rural.

No entanto, mal saíra o single e meus encontros com Guarabyra nos corredores da Odeon definiam outros rumos para nós dois, reforçados por encontros diários no bar Paisano, que ficava no térreo do prédio da gravadora. Acabamos por retomar nossa parceria e gravar um disco de dupla, o Nunca, que trazia na capa uma queda de braço entre nós, fotografada por Miguel Rio Branco e lindamente enquadrada em preto e amarelo por Waltercio Caldas Jr. A paradoxal junção do título com a queda de braço expunha simbolicamente nossa intenção de eternizar a união, confiando mais uma vez na amizade acima das eventuais discrepâncias de rumos musicais. Morando em cidades diferentes numa época em que a comunicação e os deslocamentos não eram propriamente corriqueiros, tivemos que lutar pela coerência de nossas ideias e propósitos. A gravação de Nunca, com arranjos do experiente Duprat contrapostos aos dos quase estreantes Eduardo Souto Neto e Nelson Ângelo, definiu as tendências do então ainda rock rural. A "Segunda Canção da Estrada" conclamava os errantes a voltar para casa: “Tem uma menina que eu encontrei na estrada/ Dizendo que volta comigo/ Pra descansar um pouco da vida que a gente escolheu...". E “Divina Decadência" condenava os excessos antes estimulados: "Você precisa muito de um 
remédio/ Que cure essa divina decadência/ Você anda bebendo como um bode/ Perdendo o baratinho da inocência...". Mas o principal de Nunca é que ele estabelecia a liberdade de ser uma dupla e um indivíduo ao mesmo tempo, expondo nossas desigualdades através da solução que encontramos para equiparar nossas diferenças: assinar em dupla todas as eventuais composições solo, à semelhança de Roberto e Erasmo e Lennon e McCartney.

À medida que o tempo foi passando, fomos nos distanciando cada vez mais dos limites que o rótulo impunha. No disco seguinte, Cadernos de Viagem (1975), chamamos a cantora Marisa Fossa - que se destacara alguns anos antes como vocalista do grupo O Bando - para completar o trio de vozes do qual sentíramos falta em Nunca-e formamos uma banda baseada no trio Robertinho Silva (bateria), Luiz Alves (baixo) e Tenório Jr. (teclados), juntando a esse trio basicamente jazz-bossanovístico um guitarrista de rock (Sergio Hinds, de O Terço) e um jovem e talentoso saxofonista com a cabeça ligada no fusion, Ricardo Mattos. O resultado poderia ser chamado de jazz rural... O disco vendeu abaixo da nossa média, mas foi um sucesso de crítica. Suas músicas - embaladas pela inusitada combinação de formações musicais tão diversas - contavam a história imaginária de uma viagem pelo sertão do São Francisco. Os discos seguintes, embora francamente são-franciscanos e com pouquíssimos dados de rock em sua concepção, projetaram de vez nosso estilo no mercado fonográfico, que chegou ao auge do sucesso comercial e popular na segunda metade da década de 80 , com a trilha sonora da novela mega-hit Roque Santeiro, em cuja trilha participamos com três dos principais temas: "Roque Santeiro" e "Verdades e Mentiras", interpretados por nós, e "Dona”, música nossa cantada pelo Roupa Nova.

Mas, afinal, o rock rural existe de fato ou é apenas um rótulo que serve para definir o estilo Sá, Rodrix \& Guarabyra ou Sá \& Guarabyra? Essa é uma pergunta que nos fazemos frequentemente, porque, mesmo dentro dos quase quarenta anos de nossa carreira, ele se mostrou tão legítimo em Nunca quanto ausente em Rio-Bahia, nosso disco de 97, talvez o mais - digamos assim - brasileiro de todos. Creio que essas idas e vindas em trabalhos pendendo ora para o rock, ora para uma música de raízes fincadas no regional acabaram por fazer com que público e crítica entendessem que rock rural seria apenas um rótulo para definir o indefinível do estilo próprio de um só artista ou grupo. Seguindo essa mesma linha poderíamos chamar o "Coroné Antonio Bento" (João do Vale e Luiz Wanderley) gravado por Tim Maia de "soul nordeste" ou a Nação Zumbi e Chico Science de “heavy maracatu"... A meu ver, trata-se tão somente de um esforço da mídia para encontrar aquela denominação que consiga localizar um estilo no espaço de entendimento do leitor. O problema é que o que caracteriza na verdade o trabalho desses artistas que buscam um novo mix entre o que chega de fora - artística e tecnologicamente falando - e suas raízes culturais, dentro daquele larguíssimo espectro que vai do caipira à bossa nova, é justamente a instabilidade que rege essa procura, a caça permanente à originalidade, a recusa, enfim, de rótulos. Porque o rótulo limita, e se há uma coisa

\section{Sá \& Guarabyra, Pirão de Peixe com Pimenta, Som Livre, 1977}

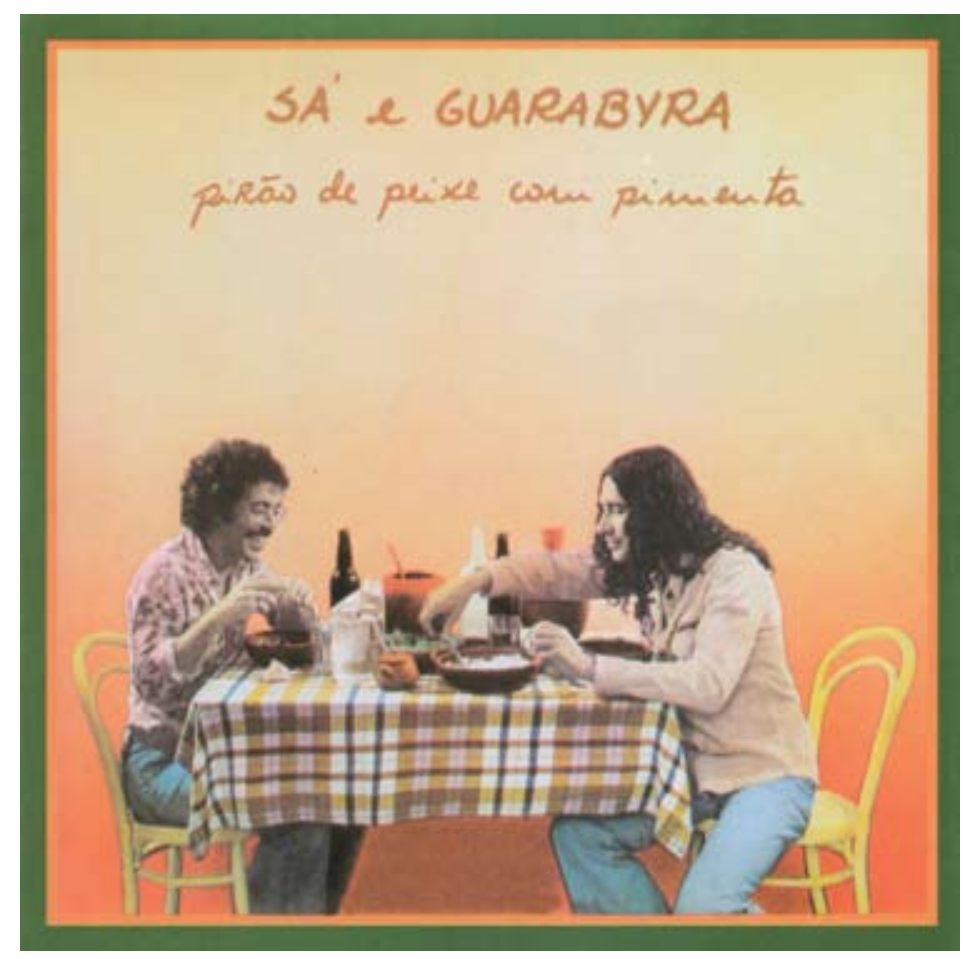




\section{Contracapa do CD \\ Sá, Rodrix \\ \& Guarabyra, coletânea \\ com os dois primeiros \\ discos do trio, \\ EMI, s.d.}

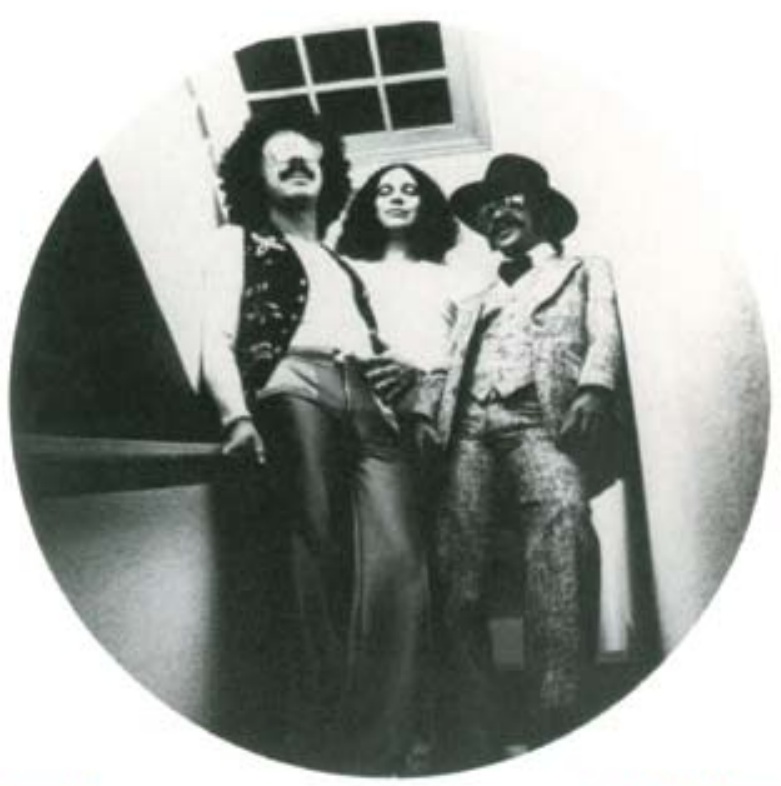

Zepelin

Ama teu vizinho como a ti mesmo

Hoje ainda é dia de rock

Cumpadre meu

Primeira cançấo da estrada

Os anos 60

\begin{abstract}
Mestre Jonas
Blue riviera

Adiante

Pindurado no vapor Juriti Butterfly
\end{abstract}

que nenhum deles deseja em seu trabalho é justamente o limite.

Com o súbito e prematuro falecimento do parceiro e amigo Zé Rodrix em maio de 2009, eu e Guarabyra seguimos levando a bandeira do nosso estilo, seja ele chamado do que for. O último disco do trio, Amanhã, com doze músicas inéditas, foi terminado um mês antes da morte de Rodrix. Nele convivem "O Dia do Rio", um xote, "Logo Eu, Saudade”, quase uma moda de viola, e "Cidades Meninas" - a tal mistura do peso do rock com o assunto do campo-com as levadas roqueiras ou urbanas, como queiram, de "Caminho de São Tomé”, "Sonho Triste em Copacabana” e "Marina, Eu Só Quero Viver". Enquanto isso, com a perspectiva de um mundo cada vez mais entregue à ganância e à inconsequência, vemos nas novas gerações um renovado interesse em colocar o rock a serviço de um ideário semelhante ao que a nossa professava nos anos
70. Neo-hippies? Que sejam, que venham, desde que tenham aprendido com nossos erros e reciclem nossos acertos setentistas. Talvez seja uma resposta necessária à música de viés depressivo que vem gotejando por aí... Por mim, sou mais o pragmatismo positivo dos Novos Baianos: "Se não há outro mundo/ Por que não viver/ Não viver nesse mundo...".

Tenho então a esperança de que o rótulo ou estilo "rock rural" tenha servido e continue a servir-sem pieguices, por favor-para a tentativa de um mundo melhor, com seus enfoques na preservação ambiental (onde foi um pioneiro musical no Brasil), numa vida com menos ansiedade, na satisfação com o que é suficiente e na negação da ganância e da ambição desmedidas, como um segmento musical libertário por origem, sem excessivos compromissos com modismos ou mercados e focado numa ética de respeito à vida. 


\section{NOTA BIOGRÁFICA}

Nasci em 15 de outubro de 1945 em Laranjeiras, Rio de Janeiro. Morei em Vila Isabel, passei a infância ouvindoe cantando os sambas de Noel Rosa em saraus mensais promovidos por meu pai, Sylvio, que também me ensinou os primeiros acordes no violão. Mudei-me depois para a Tijuca e formei com alguns amigos o Nouvelle Vague, um grupo adolescente influenciado pela bossa nova, que - como tantos outros da época - tocava apenas em festinhas de clubes sociais. Em 1965 o baixista do grupo, Mariozinho Pires, levou-me à gravadora Odeon, onde tive minhas primeiras músicas gravadas-com sucesso-porPery Ribeiroe Rosa Maria. No mesmo ano minha primeira parceira e também primeira influência no instrumento, a cantora e compositora Luhli, gravou um disco na Philips com três músicas minhas. Com ela, Sidney Miller, o futuro cineasta Paulo Thiago, Marco Antonio Menezes, a cantora Soninha Ferreira (hoje no Quarteto em Cy) e eu formamos o Grupo Mensagem, assim batizado por Armando Costa, do emblemático Grupo Opinião. O Opinião colocou os jovens do Mensagem ao lado de ícones da época, como Baden Powell, Aracy de Almeida, Ismael Silva, Padeirinho da Mangueira e MPB-4, num musical chamado Samba Pede Passagem, que influenciou profundamente os meus rumos profissionais. Passei, assim, a dedicarme à chamada "música de protesto", com parcerias com o teatrólogo e poeta Chico de Assis, a quem havia sido apresentado por outro poeta, Nelson Lins de Barros. Foi na casa de Nelson, em 1966, que fui apresentado a Guarabyra, recém-chegado do interior são-franciscano da Bahia. Na mesma época fiz parte da equipe - como colunista de música - do jornal-escola $O$ Sol, dirigido por Reynaldo Jardime Martha Alencar, aprendendo o ofício com gente do quilate de Nelson Rodrigues e Otto Maria Carpeaux. Já então desgostoso com a ação da censura ditatorial e consequente falta de perspectivas musicais, dediquei-me a terminar o curso de direito na Faculdade Candido Mendes e tentar o ingresso na carreira diplomática. O AI-5, de 1968, levou-me, no entanto, já advogado e oficial de chancelaria, a deixar o Itamaraty e partir para ser programador musical da rádio JB. Convidado por meu ex-professor de jornalismo Reynaldo Jardim, projetei e editei o Plug, caderno de música e cinema, no jornal Correio da Manhã, onde tive oportunidade de trabalhar com Zuenir Ventura, Newton Carlos, Washington Novaes, Ana Arruda, Ruy Castro, Wally Salomão e Torquato Neto. Sob o estímulo e com a parceria de Torquato, voltei a compor. Acabei firmando uma parceria regular com outro amigo, Zé Rodrix, recém-saído do Som Imaginário, grupo que acompanhava Milton Nascimento. Em 1971, o final de um primeiro casamento levou-me a ser hospedado pelo amigo Guarabyra no apartamento de Ipanema que ele, Guarabyra, dividia com os jornalistas José Trajano e Toninho Neves. Lá, eu e Rodrix passamos a ensaiar uma dupla, que então fatalmente virou um trio. E o resto são quase 40 anos de rock rural, como foi contado anteriormente.

Vivo atualmente em Belo Horizonte, casado com a turismóloga Verlaine de Sá, e tenho cinco filhos: Miguel, 36, músico e jornalista; Dora, 32, atriz; Tomaz, 27, cantor e compositor; Vicente, 16, estudante; e Diogo, 3. Tenho também uma neta, Isabel, de 2 anos. 